\title{
INSTRUMEN UNTUK MENILAI VALIDITAS VIDEO PEMBELAJARAN FISIKA BERBASIS CTL PADA MATERI FLUIDA
}

\section{INSTRUMENTS TO ASSESS THE VALIDITY OF PHYSICAL LEARNING VIDEOS CTL BASED ON FLUID MATERIALS}

\author{
Dira Novisya ${ }^{{ }^{*}}$ dan Desnita ${ }^{2}$ \\ ${ }^{1}$ Mahasiswa Program Studi Magister Pendidikan Fisika, FMIPA Universitas Negeri Padang, Padang, Indonesia \\ ${ }^{2}$ Dosen Program Studi Magister Pendidikan Fisika, FMIPA Universitas Negeri Padang, Padang, Indonesia \\ *Email: diranovisya11@gmail.com
}

Diterima: 21 Juli 2020. Disetujui: 23 Juli 2020. Dipublikasikan: 30 September 2020

\begin{abstract}
Abstrak: Penelitian ini bertujuan untuk menghasilkan instrumen validitas yang berkualitas yang digunakan dalam menilai validitas video pembelajaran fisika berbasis CTL pada materi fluida. Instrumen yang dinilai terdiri atas instrumen validitas isi, konstruk dan bahasa. Jenis penelitian ini adalah penelitian pengembangan. Subjek penelitian terdiri atas 3 validator terkait yang ahli pada dibidangnya. Penilaian instrumen validitas ini menggunakan lembar penilaian instrumen. Berdasarkan dari pengolahan dan analisis data yang telah dilakukan menunjukan bahwa instrumen berada dalam kategori valid dengan nilai rata-rata untuk validasi isi sebesar 0,89 , nilai rata-rata untuk validasi konstruk sebesar 0,91 , dan nilai rata-rata untuk validasi bahasa sebesar 0,83 . Dengan demikian, instrumen layak digunakan untuk mengukur validitas video pembelajaran fisika berbasis CTL pada materi fulida.
\end{abstract}

Kata Kunci: Instrumen, Penilaian, $C T L$, Fluida

Abstract: This study aims to produce a quality validity instrument used in assessing the validity of CTL-based physics learning videos on fluid material. The instrument assessed consisted of instruments of content validity, construct and language. This type of research is development research. The research subjects consisted of 3 related validators who were experts in their fields. This instrument validity assessment uses the instrument assessment sheet. Based on the data processing and analysis that has been done shows that the instrument is in the category of valid with an average value for content validation of 0.89 , the average value for construct validation of 0.91 , and the average value for language validation of .83. Thus, the instrument is feasible to use to measure the validity of CTL-based physics learning videos on fulida material.

Keywords: Instrument, Assessment, CTL, Fluid

\section{PENDAHULUAN}

Fisika merupakan bagian dari rumpun IPA yang dibangun dari hasil penelitian ilmiah [1,2]. Fisika mengkaji objek-objek berupa benda serta peristiwa yang ada di alam [3]. Kajian berupa benda dan peristiwa berhubungan dengan prilaku dan struktur yang ada disekitarnya saling berinteraksi antara satu dengan lainnya. Adapun lingkupannya mencakup materi fakta, konsep, prinsip yang berhubungan dengan fenomena yang ada di alam [4]. Selain fisika ini mengkaji peristiwa alam, tentunya fisika juga memiliki peran penting terhadap kehidupan manusia. Hal Ini ditemukan banyaknya aktivitas manusia maupun teknologi menerapkan prinsip ilmu fisika [5,6]. Wulandari \& Mundilarto [7] juga mengemukakan menggunakan prinsip ilmu fisika merupakan ilmu dasar dalam penemuan dan perkembangan pengetahuan maupun teknologi saat ini. Ilmu fisika dapat menjelaskan bagaimana dunia itu berkerja [8]. Mengingat besarnya pengaruh fisika, tentunya sangat perlu untuk dipelajari oleh siswa ditingkat SMA.
Ditingkat SMA, fisika salah satu mata pelajaran yang wajib diikuti siswa pada jalur MIPA. Selain mata pelajarannya wajib, juga berperan penting untuk melatih dan mengembangkan kemampuan berpikir siswa secara kritis, kreatif, inovatif dalam mengambil keputusan dari masalah yang ditemui terkait peristiwa sehari-hari maupun teknologi [9-11]. Mengambil keputusan tentunya juga harus terampil dalam menggunakan konsep dan prinsip fisika [12]. Pada proses pembelajaran, guru harus mengorientasikan siswa dengan menanamkan konsep, mengembangkan keterampilan ilmiahnya dan meningkatkan keterampilan berpikirnya [13]. Agar dapat mengorientasikan pembelajaran tersebut tentunya siswa harus berinteraksi langsung dengan fenomena yang di alam agar dapat melatih, mengembangkan kemampuan berpikir, dan menemukan keterkaitan antara konsep dipelajari dengan fenomena yang dihadapi $[14,15]$. Dikarenakan fisika mempelajari berbagai fenomena dan kejadian alam dalam 
kehidupan sehari-hari, maka dibutuhkan suatu media pembelajaran yang mewadahi semua fenomena dan peristiwa tersebut agar mempermudah siswa dalam mengamati dan mempelajarinya. Dengan menggunakan media dalam proses pembelajaran dapat merangsang pikiran, perhatian, dan minat siswa dalam belajar [16-18]. Salah satunya termasuk pada video.

Video merupakan media berbasis digital yang berisikan objek bergerak beserta dengan suara alamiahnya. Video juga dapat menampilkan fenomena fisika secara nyata, kompleks, dan bervariasi. Penggunaan video sangat efektif diterapkan dalam pembelajaran. Selain menampilkan fenomena secara autentik, juga dapat membuat siswa tertarik dan termotivasi dalam belajar $[19,20]$.

Memasuki era sekarang, menggunakan media digital tidaklah cukup dalam proses pembelajaran. Media digital yang digunakan harus benar-benar membelajarkan siswa dengan memberikan pengalaman dan mengajak siswa membangun pengetahunnya sendiri dari konsep yang dipelajari [21]. Tuntutan era sekarang selain melatih siswa menggunakan IT juga harus melatih keterampilan tingkat tinggi siswa (kritis, kreatif, kolaboratif dan komunikatif) agar berhasil dalam kehidupan maupun dunia kerja [22]. Agar video diterapkan sesuai dengan tuntutan, maka diperlukan pendekatan yang tepat dalam menerapkan video. Wijayanti [23] mengemukakan menggunakan pendekatan dapat menggali dan mengembangkan pengetahuan siswa secara konkrit. Salah satu pendekatan yang tepat dalam pengembangan video adalah CTL.

Pendekatan CTL dapat memberikan pengaruh positif terhadap proses pembelajaran [24]. Selain menekankan pembelajaran aktif juga mengaitkan pembelajaran dengan kehidupan nyata. CTL dapat melatih dan mengembangkan keterampilan tingkat tinggi siswa dengan mentransfer, mengumpulkan, menganalisa, mensintesis informasi menggunakan berbagai sumber untuk menjawab dari fenomena yang dilihat dan menguasai konsep secara utuh $[25,26]$. Ada 10 karakteristik pembelajaran CTL yaitu; (1) menempatkan siswa sebagai subjek belajar, (2) mengarahkan pembelajaran berkelompok, (3) mengaitkan materi dengan kehidupan nyata, (4) mengembangkan kemampuan didasarkan pengalaman, (5) memperoleh kepuasan diri dalam belajar, (6) membangun kesadaran diri, (7) membangun pengetahuan dari pengalaman, (8) memonitor dan mengembangkan pembelajaran sendiri, (9) belajar dimana saja, dan (10) dapat mengukur seluruh perkembangan kemampuan siswa [27].

Agar video yang diterapkan sesuai dengan tuntutan dan pendekatan yang digunakan. Terlebih dahulu dilakukan pengujian kualitas video yang dikembangkan. Pengujian dilakukan dengan melalui valid, praktis dan efektif [28]. Sebelum pengujian dilakukan terhadap video dikembangkan, terlebih dahulu dilakukan pengujian instrumen yang akan digunakan. Pengujian instrumen bertujuan agar instrumen yang digunakan benar-benar mengukur kualitas video yang dikembangkan.

Pengujian instrumen dengan melakukan uji validitas instrumen. Uji validitas instrumen merupakan unsur utama yang harus dilewati agar memperoleh instrumen yang berkualitas [29]. Uji validitas instrumen dengan memberikan lembaran penilaian kepada tim validator [30-32]. Tim validator akan menilai tingkat kevalidtan instrumen yang digunakan. Kevalidan instrumen menunjukan keakurasian instrumen dalam melakukan fungsi ukurnya yang dapat mengukur keadaan sebenarnya [33-34].

Untuk memperoleh instrumen yang benarbenar berkualitas maka dilakukan dengan prosedur ilmiah. Artikel ini akan memaparkan kualitas instrumen yang digunakan untuk menguji kevalidan video pembelajaran fisika berbasis CTL pada materi fluida. Penelitian ini sangat penting dilakukan agar memperoleh instrumen validasi yang berkualitas yang dapat mengukur kevalidan video yang dikembangkan.

\section{METODE PENELITIAN}

Penelitian ini menggunakan jenis penelitian pengembangan (research and development) yang digunakan untuk menghasilkan dan menvalidasi produk [35]. Adapun prosedur yang dilakukan dalam penelitian ini dengan melakukan analisis kompetensi, merumuskan indikator dan tujuan penelitian, membuat kisi-kisi instrumen, membuat butir instrumen, validasi ahli pada tahap satu, analisis data, revisi, validasi ahli pada tahap dua, analisis data dan final [36].

Subjek penelitian adalah tiga validator ahli. Penilaian instrumen validasi menggunakan lembar penilaian yang berisikan skala likert. Ada lima skala likert yang terdapat didalamnya. Disetiap skala likert memiliki skor masingmasing yang akan dipilih oleh team validator berdasarkan pandangannya terhadap instrumen yang dikembangkan [37]. Adapun rentang skala likert yang terdapat di dalamnya adalah sangat baik (skor 5), baik (skor 4), cukup (skor 3), kurang (skor2) dan sangat kurang (skor 1).

Data yang diperoleh dari masing-masing validator akan diproses melalui rumus Aikens'V seperti persamaan di bawah ini.

$$
V=\frac{2 s}{[n(c-1)]}
$$

Nilai yang diperoleh dari Aikens'V dikategorikan seperti pada Tabel 1 [33]. 
Tabel 1. Kategori Validasi

\begin{tabular}{cc}
\hline Interval & Kategori \\
\hline$\geq 0.6$ & Valid \\
$<0.6$ & Tidak Valid \\
\hline
\end{tabular}

\section{HASIL DAN PEMBAHASAN}

Penelitian ini dilakukan untuk mengungkapkan kualitas instrumen validasi yang dikembangkan untuk menilai validitas video pembelajaran fisika berbasis CTL pada materi fluida. Ada tiga instrumen yang akan dinilai oleh validator yaitu instrumen validasi isi, instrumen validasi konstruk, dan instrumen validasi bahasa.
Masing-masing instrumen ini dinilai oleh tim validator yang merupakan ahli dalam bidangnya. Terdapat tiga validator yang menilai kualitas instrumen yang dikembangkan yaitu validator ahli fisika, validator ahli pembelajaran, dan validator ahli bahasa. Validator ahli fisika menilai instrumen validasi isi, validator ahli pembelajaran menilai instrumen validasi konstruk, dan validator ahli bahasa menilai instrumen validasi bahasa.

Berdasarkan dari tiga instrumen yang dinilai terdapat beberapa saran yang diberikan oleh validator terkait dari instrumen yang dikembangkan seperti terlihat pada Tabel 2.

Tabel 2. Rangkuman Saran Validator

\begin{tabular}{|c|c|c|}
\hline Instrumen & Sebelum Revisi & Setelah Revisi \\
\hline \multirow[t]{3}{*}{$\begin{array}{l}\text { Instrumen validasi } \\
\text { isi }\end{array}$} & $\begin{array}{l}\text { Pernyataan terkait contoh-contoh } \\
\text { tayangan video terkait dengan peristiwa } \\
\text { sehari-hari memiliki sis iketerbaruan", } \\
\text { Diuraikan menjadi } 3 \text { pernyataan. yaitu a) } \\
\text { terkait peristiwasehari-hari, b) terkait } \\
\text { dengan teknologi, dan c) memiliki } \\
\text { keterbaruan. }\end{array}$ & $\begin{array}{l}\text { Pernyataan sudah diuraikan } \\
\text { menjadi tiga pernyataan. } \\
\text { a. Contoh-contoh pada tayangan } \\
\text { video terkait dengan peristiwa } \\
\text { sehari-hari } \\
\text { b. Contoh-contoh pada tayangan } \\
\text { video terkait dengan teknologi } \\
\text { c. Contoh-contoh pada tayangan } \\
\text { video memiliki sisi } \\
\text { keterbaruan" }\end{array}$ \\
\hline & $\begin{array}{l}\text { Pernyataan tayangan video yang terkait } \\
\text { peristiwa sehari-hari dapat digunakan } \\
\text { untuk melakukan eksplorasi", diganti } \\
\text { menjadi "tayangan video dapat digunakan } \\
\text { untuk melakukan eksplorasi" }\end{array}$ & $\begin{array}{l}\text { Pernyataan sudah diganti menjadi } \\
\text { "Tayangan video dapat digunakan } \\
\text { untuk melakukan eksplorasi" }\end{array}$ \\
\hline & Pernyataan overlap dihapuskan & Pernyataan overlap sudah dihapus \\
\hline \multirow[t]{2}{*}{$\begin{array}{l}\text { Instrumen validasi } \\
\text { konstruk }\end{array}$} & $\begin{array}{l}\text { Pernyataan mengenai kata respon menjadi } \\
\text { kata interaksi }\end{array}$ & $\begin{array}{l}\text { Pernyataan sudah diganti menjadi } \\
\text { kata interaksi }\end{array}$ \\
\hline & $\begin{array}{l}\text { Pernyataan mengenai penyajian video } \\
\text { dapat menumbuhkan motivasi belajar dan } \\
\text { meningkatkan kreativitas siswa", dirinci } \\
\text { menjadi } 2 \text { pernyataan yaitu a) menilai } \\
\text { motivasi dan b) menilai kreativitas }\end{array}$ & $\begin{array}{l}\text { Pernyataan sudah dirincikan } \\
\text { menjadi } 2 \text { pernyataan } \\
\text { a. Penyajian video pembelajaran } \\
\text { dapat menumbuhkan motivasi } \\
\text { belajar siswa } \\
\text { b. Penyajian video pembelajaran } \\
\text { dapat meningkatkan } \\
\text { kreativitas siswa }\end{array}$ \\
\hline $\begin{array}{l}\text { Instrumen validasi } \\
\text { bahasa }\end{array}$ & $\begin{array}{l}\text { Konsisten dalam penggunaan kata dan } \\
\text { tanda baca }\end{array}$ & $\begin{array}{l}\text { Penggunaan kata dan tanda baca } \\
\text { sudah konsisten dibuat }\end{array}$ \\
\hline
\end{tabular}

Berdasarkan Tabel 2, instrumen validasi diperbaiki sesuai dengan saran yang diberikan oleh validator agar menghasilkan instrumen validasi yang valid
Hasil penilaian instrumen validasi isi dapat dilihat pada Gambar 1. 


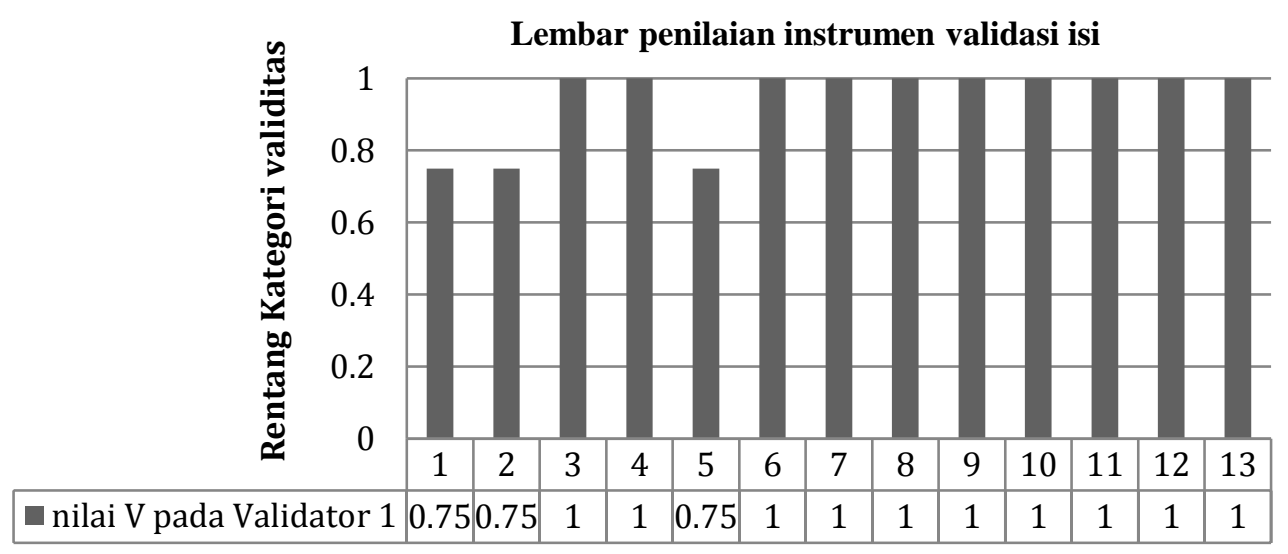

Gambar 1. Hasil Lembar Penilaian Instrumen Validasi Isi

Gambar 1 menunjukan ada tiga belas indikator yang digunakan untuk menilai instrumen validasi isi. Dari tiga belas indikator secara keseluruhan nilai diperoleh berada dikisaran besar dari 0,6 dengan kategori valid. Hal ini berarti bahwa instrumen validitas isi dapat digunakan untuk mengukur validasi isi pada video pembelajaran.

Adapun hasil penilaian instrumen validasi konstruk dapat dilihat Gambar 2.

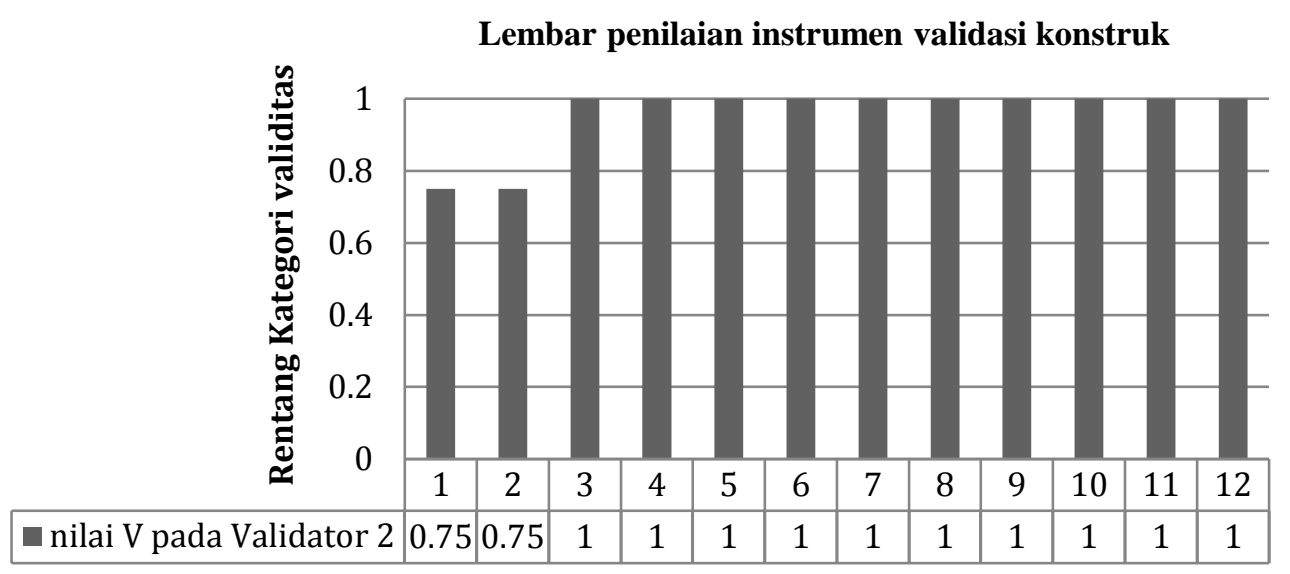

Gambar 2. Hasil Lembar Penilaian Instrumen Validasi Konstruk

Gambar 2 menunjukan ada dua belas indikator yang digunakan untuk menilai instrumen validasi konstruk. Dari dua belas indikator secara keseluruhan nilai diperoleh berada dikisaran besar dari 0,6 dengan kategori valid. Hal ini berarti bahwa instrumen konstruk dapat digunakan untuk menilai validasi konstruk video pembelajaran fisika.

Hasil penilaian instrumen validasi bahasa dapat dilihat pada Gambar 3.

Gambar 3 menunjukan ada dua belas indikator yang digunakan untuk menilai instrumen validasi bahasa. Dari dua belas indikatoryang digunakan menunjukan bahwa instrumen validasi bahasa berada kategori valid dengan nilai melebih dari 0,6. Hal ini berarti bahwa instrumen bahasa dapat digunakan untuk menilai validasi bahasa yang terdapat di dalam video pembelajaran fisika.
Berdasarkan Tabel 3 menunjukan instrumen validasi isi berada kategori valid dengan rata-rata keseluruhan sebesar 0,89. Validnya insrumen ditinjau dari aspek 1 mengemukakan instrumen yang dihasilkan dapat mengukur video sesuai dari permasalahansebenarnya dan sesuai dengan tujuan yang dicapai. Kemudian ditinjau dari aspek 2 instrumen yang dikembangkan memiliki petunjuk yang jelas, mudah digunakan untuk menilai, memiliki ketepatan butir yang dinilai, memiliki kejelasan umpan balik dalam menilai. Adapun peninjauan aspek 3 ukuran dan jenis tulisan instrumen dapat dibaca dan memiliki keteraturan konsisten dalam penyajian. Dari ketiga aspek penilaian instrumen validasi isi sudah memenuhi dan layak digunakan dalam menilai validitas isi pada video. 


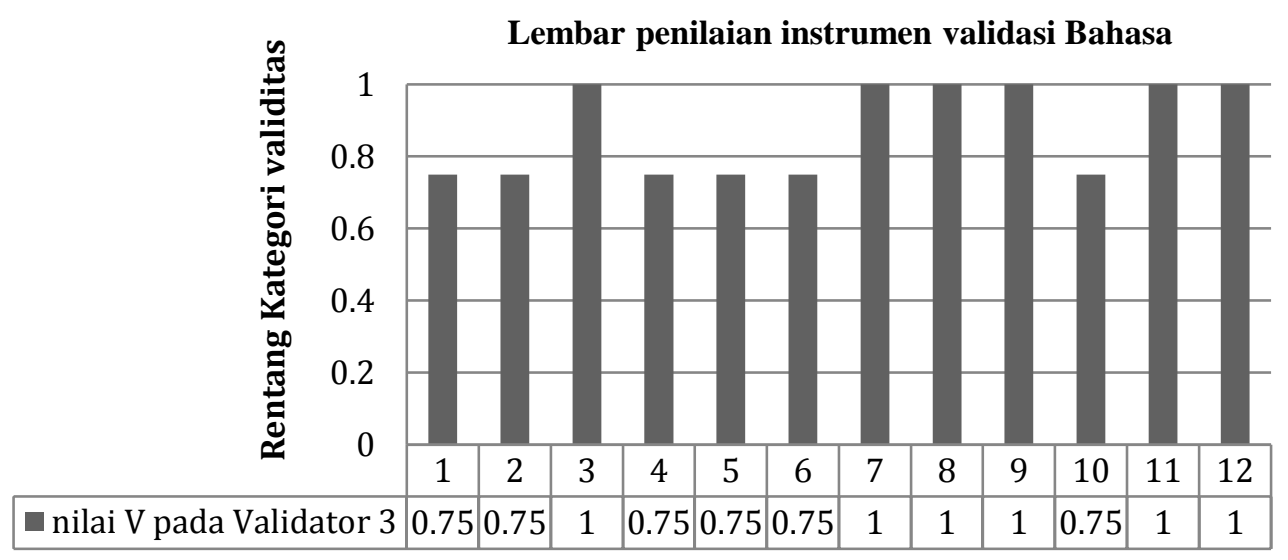

Gambar 3. Hasil Lembar Penilaian Instrumen Validasi Bahasa

Untuk nilai rata-rata validasi isi per aspek dapat dilihat pada Tabel 3.

Tabel 3. Rata-Rata Penilaian Instrumen Validasi Isi Validator 1

\begin{tabular}{lcc}
\hline $\begin{array}{l}\text { Aspek Penilaian } \\
\text { Instrumen }\end{array}$ & V Rata-Rata & Kategori \\
\hline Aspek 1 & 0.75 & Valid \\
Aspek 2 & 0.94 & Valid \\
Aspek 3 & 1 & Valid \\
Rata-rata & 0.89 & Valid \\
\hline
\end{tabular}

Untuk nilai rata-rata validasi konstruk per aspek dapat dilihat pada Tabel 4.

Tabel 4. Rata-Rata Penilaian Instrumen Validasi Konstruk Validator 2

\begin{tabular}{lcc}
\hline $\begin{array}{l}\text { Aspek Penilaian } \\
\text { Instrumen }\end{array}$ & V Rata-Rata & Kategori \\
\hline Aspek 1 & 0.75 & Valid \\
Aspek 2 & 1 & Valid \\
Aspek 3 & 1 & Valid \\
Rata-rata & 0.91 & Valid \\
\hline
\end{tabular}

Berdasarkan Tabel 4 bahwa instrumen validasi konstruk berada dalam kategori valid dengan nilai rata-rata keseluruhan sebesar 0,91. Validnya instrumen menunjukan bahwa instrumen dapat mengukur validitas konstruk video pembelajaran fisika berbasis CTL.

Untuk nilai rata-rata validasi isi per aspek dapat dilihat pada Tabel 5.
Tabel 5. Rata-Rata Penilaian Instrumen Validasi Bahasa Validator 3

\begin{tabular}{lcc}
\hline $\begin{array}{l}\text { Aspek Penilaian } \\
\text { Instrumen }\end{array}$ & V Rata-Rata & Kategori \\
\hline Aspek 1 & 0.75 & Valid \\
Aspek 2 & 0.81 & Valid \\
Aspek 3 & 0.95 & Valid \\
Rata-rata & 0.83 & Valid \\
\hline
\end{tabular}

Berdasarkan Tabel 5 menggambarkan bahwa instrumen validasi bahasa berada kategori valid. Validnya instrumen bahasa menunjukan bahawa instrumen dapat digunakan untuk mengukur bahasa pada video pembelajaran.

Dengan demikian, instrumen validasi yang digunakan untuk menilai validitas video berada dalam kategori valid.

\section{KESIMPULAN}

Berdasarkan pengolahan dan analisis data yang telah dilakukan terkait penilaian instrumen validasi isi, instrumen validasi konstruk, dan instrumen validasi bahasa menunjukkan bahwa instrumen valid. Hal ini ditinjau dari nilai ratarata validasi isi sebesar 0,89 , nilai rata-rata validasi konstruk sebesar 0,91 dan nilai rata-rata validasi bahasa sebesar 0,83. Dengan demikian, instrumen validasi berkualitas sehingga dapat mengukur validasi video pembelajaran.

\section{DAFTAR PUSTAKA}

[1] Ubaidillah, M. (2018). Metode Field Trip untuk Meningkatkan Konsep Fisika dan Mengakses Keterampilan Proses Sains. Jurnal Pendidikan Sains (JPS), 6(2). 93-103.

[2] Saputra, R., Susilawati., \& Ni Nyoman, S, P, V. (2020). Pengaruh Penggunaan Media Simulasi Phet (Physics Education 
Technology) Terhadap Hasil Belajar Fisika. Journal Pijar MIPA, 15(2). 110-115.

[3] Budiarti, Nurul. (2015). Efektivitas Metode Diskusi dengan Pendekatan Open-Ended Questions untuk Meningkatkan Hasil Belajar Fisika Siswa Kelas X SMA Muhammadiyah Kota Tegal. JRKPF UAD, 2(1). 29-32

[4] Sani, L. N., Satutik, R., \& Hikmawati. (2018). Pengaruh Model Pembelajaran Direct Instruction dengan Media Macromedia Flash Terhadap Hasil Belajar Fisika Kelas XI SMAN 1 Kopang. Journal Pijar MIPA, 13(1). 13-18

[5] Kumalasari, M., \& Moch, B. T. (2018). Pengembangan Virtual Physics World Sebagai Media Pembelajaran Kesetimbangan Benda Tegar Untuk Meningkatan Keterampilan Penerapan Ilmu Fisika Sehari-hari. Jurnal Inovasi Teknologi Pendidikan, 5(2). 165-179.

[6] Zohar, B. R., \& R. T. (2020). The Influence of Inquiri-Based Remote Observations Via Powerful Optik Robotic Telescopes on High School Students' Conceptions of Physics and of Learning Physics. Journal of Science Education and Technology, https://doi.org/10.1007/s10956020-09842-8.

[7] Wulandari, W. T., \& Mundilarto. (2016). Pengembangan Perangkat Pembelajaran Fisika Aktif Tipe Learning Tournament Berbasis Local Wisdo. Cakrawala Pendidikan, 35(3). 365-377.

[8] Yani \& Asrizal. (2019). Pembuatan Tool Pemodelan Bandul Matematis dengan Pengontrolan Panjang Tali Otomatis untuk Analisis Video Tracker. Pillar of Physics, 12. 76-83

[9] Kemendikbud. (2017). Model Silabus Mata Pelajaran Sekolah Menengah Atas/ Madrasah Aliyah (SMA/MA) Mata Pelajaran Fisika. Jakarta: Kementerian Pendidikan dan Kebudayaan

[10] Mukarramah, M., Ni, N. S. P. V., \& Ahmad, H. (2019). Pengaruh Model Pembelajaran CORE Terhadap Penguasaan Konsep Fisika Peserta Didik Kelas XI MAN Lombok Barat. Journal Pijar MIPA, 14(3). 176-183

[11] Murniati, Syahrini, A., \& Hairunisya, S. (2020). Pengaruh Model Pembelajaran Connecction, Organizing, Reflection, Extending (Core) Terhadap Pemahaman Konsep Fisika dan Kemampuan Berpikir Kritis. Journal Pijar MIPA, 15(2). 116-121.

[12] Sugiarto, M., Bunga, D. A., \& Ahmad, Y. 2016. Studi Kemampuan Penyelesaikan Soal-Soal Fisika Menurut Langkah Pemecahan Masalah Polya Pada Peserta Didik XI IPA SMA Negeri 1 Baraka Kabupaten Enrekang. Jurnal Sains dan Pendidikan Fisika, 12(2). 183-191.

[13] Sapriadi, S., A, S., A, S., A, M., D, S., S, A. S. L., \& N, H. (2019). Effect of Higher Order
Thinking Virtual Laboratory (Hotvl) in Electric Circuit on Stedents' Creative Thinking Skills. Journal of Physics, 1204. 16.

[14] Muslina, Abdul, H., \& Ibnu, K. (2017). Kelayakan media animasi hukum Newton ii tentang gerak pada bidang miring dan katrol di SMA kabupaten Aceh besar. JIPI (Jurnal IPA dan Pembelajaran IPA), 1(1). 64-72.

[15] Kurniawati, H., Desnita., \& Siswoyo. (2017). Pengembangan Buku Pengayaan Pengetahuan Kajian Fisika dalam Alat Musik Kordofon untuk Pembelajaran Bermakna. Prosising Seminar Nasional Fisika (eJournal), dilangsa pada tanggal 24 maret 2020, p-ISSN: 2339-0654, e-ISSN: 24769398. 13-20

[16] Arsyad, A. (2014). Media Pembelajaran, Edisi Revisi. Jakarta: Raja Grafindo.

[17] Sadiman, A. (2014). Media Pendidikan. Jakarta: Raja Grafindo.

[18] Al-Idrus, S. Q. J., Hikmawati., \& Wahyudi. (2015). Pengaruh Model Pembelajaran Berbasis Masalah Berbantuan Video Kartun Terhadap Hasil Belajar Fisika Siswa Kelas XI SMAN 1 Surkur Tahun Ajaran 2014/2015. Jurnal Pijar MIPA, 10(1). 22-25

[19] Wanda, A. R. (2014). Pengembangan Media Video Pembelajaran Berbasis Masalah Materi Pecahan Pada Siswa Kelas IV Sekolah Dasar. Pelangi Pendidikan, 21(2) 94-105.

[20] Erviani, R. E., Sutarto., \& Indrawati. 2016. Model Pembelajaran Instruction, Doing dan Evaluating (MPIDE) disertai Resume dan Video Fenomena Alam dalam Pembelajaran Fisika di SMA. Jurnal Pembelajaran Fisika, 5(1). 53-59.

[21] Wahyuningsih., Jamaluddin., \& Karnan. (2015). Penerapan Pembelajaran Biologi Berbasis Macromedia Flash dan Implikasinya terhadap Keterampilan Metakognitif dan Penguasaan Konsep Siswa Kelas VIII SMPN 6 Mataram. Jurnal Pijar MIPA, 10(1). 41-46

[22] The Partnership for 21st Century Learning. (2019). Framework for 21st Century Learning.

[23] Wijayanti, A. (2016). Implementasi Model Pembelajaran Kooperatif Tipe TGT sebagai Upaya Meningkatkan Pemahaman Konsep Fisika Dasar Mahasiswa Pendidikan IPA. Jurnal Pijar MIPA, 11(2). 15-21.

[24] Mangesa, R.T. (2016). Implentasi pendekatan kontekstual dalam pembelajaran praktik instalasi listrik. Jurnal Kependidikan, 46(1):110-120. 
[25] Ranam, S., \& Dini, A. (2017). Pendekatan Contextual Teaching Learning dalam Pembelajaran Berbasis Kurikulum 2013. Research and Devepment Journal of Education, 3(2). 131-144.

[26] Huda, N.,\& Hikmawati, K. (2019). Pengaruh Pendekatan Kontekstual Berbantuan Alat Peraga Terhadap Penguasaan Konsep dan Kemampuan Pemecahan Masalah Fisika. Jurnal Pijar MIPA, 14 (1). 62-72.

[27] Sanjaya, W. (2009). Strategi Pembelajaran. Jakarta: Kencana.

[28] Nieveen. N. (2007). Formative Evaluation in Educational Design Research. An Introductional to Eduacational Design Research. Procedings Of the seminar Conducted at the east china normal university, shanghai. 23-26.

[29]Pada, A.U.T., Siti.S.M., \& Bambang. S. (2018). Construct Validity Of Creative Thinking Skills Instrument For Biology Student Teachers In The Subject Of Human Physiology. Jurnal Penelitian Dan Evaluasi Pendidikan, 22(2). 119129.

[30]Zulfadli, D., Desnita., Festiyed., \& Syafriani. (2019). Analisis Sajian Buku Ajar Fisika SMA Kelas X Semester 1 Terkait Komponen Contextual Teaching and Learning (CTL). Pillar of Physics Education, 12(3). 473-480.

[31] Maiyena, S., \& Venny, H. (2017). Praktikalitas Video Tutorial pada Matakuliah Eksperimen Fisika untuk Meningkatkan Keterampilan Proses Sains Mahasiswa. Jurnal Ilmiah Pendidikan Fisika Al-BIRuNi, 6(1). 75-83.

[32] Trianto. (2012). Model-model Pembelajaran Terpadu. Jakarta: Bumi Aksara.

[33] Azwar. S. (2015). Reliabilitas dan Validitas. Pustaka Pelajar:Yogyakarta.

[34]Festiyed (2017). Evaluasi Pembelajaran Fisika. Padang: Sukabina Press.

[35]Borg, W.R. \& Gall, M.D. (2003). Educational research: anintroduction. 4th Edition. New York:Longman Inc.

[36] Djaali \& Muljono, P. (2008). Pengukuran Dalam Bidang Pendidikan. Jakarta: PT Grasindo

[37] Sugiyono. (2012). Metode Penelitian Kuantitatif, Kualitatif, dan $R \& D$. Bandung : Alfabeta.. 